Article

\title{
Morphine Attenuates Apically-Directed Cytokine Secretion from Intestinal Epithelial Cells in Response to Enteric Pathogens
}

\author{
Amanda J. Brosnahan ${ }^{1,2}$, Bryan J. Jones ${ }^{1}$, Cheryl M. Dvorak ${ }^{1}$ and David R. Brown ${ }^{1, *}$ \\ 1 Department of Veterinary and Biomedical Sciences, College of Veterinary Medicine, University of \\ Minnesota, 1988 Fitch Avenue, Saint Paul, MN 55108-6010, USA; \\ E-Mails: jone0803@umn.edu (B.J.J.); dvora013@umn.edu (C.M.D.) \\ 2 Department of Science, Concordia University, 1282 Concordia Avenue, Saint Paul, \\ MN 55104-5494, USA; E-Mail: brosnahan@csp.edu \\ * Author to whom correspondence should be addressed; E-Mail: brown013@umn.edu; \\ Tel.: +1-612-624-0713; Fax: +1-612-625-0204.
}

Received: 26 November 2013; in revised form: 17 March 2014 / Accepted: 20 March 2014 /

Published: 2 April 2014

\begin{abstract}
Epithelial cells represent the first line of host immune defense at mucosal surfaces. Although opioids appear to increase host susceptibility to infection, no studies have examined opioid effects on epithelial immune functions. We tested the hypothesis that morphine alters vectorial cytokine secretion from intestinal epithelial cell (IPEC-J2) monolayers in response to enteropathogens. Both entero-adherent Escherichia coli O157:H7 and entero-invasive Salmonella enterica serovar Typhimurium increased apically-directed IL-6 secretion and bi-directional IL-8 secretion from epithelial monolayers, but only IL-6 secretion evoked by $E$. coli was reduced by morphine acting through a naloxone-sensitive mechanism. Moreover, the respective type 4 and 5 Toll-like receptor agonists, lipopolysaccharide and flagellin, increased IL-8 secretion from monolayers, which was also attenuated by morphine pretreatment. These results suggest that morphine decreases cytokine secretion and potentially phagocyte migration and activation directed towards the mucosal surface; actions that could increase host susceptibility to some enteric infections.
\end{abstract}

Keywords: morphine; opioid receptors; small intestine; epithelial cell; Escherichia coli; Salmonella enterica; interleukin-6; interleukin-8; Toll-like receptors; swine 


\section{Introduction}

Morphine and other opioid receptor agonists alter systemic innate and adaptive immune responses and increase host susceptibility to infection [1]. For example, impairments in neutrophil function, macrophage phagocytosis, $\mathrm{T}$ lymphocyte cytokine production, and B cell antigen presentation occur after exposure to morphine. In some cases, these effects are mediated through mu-, delta- or kappa-opioid receptors (MOR, DOR, and KOR, respectively), transcripts of which have been detected in human immune cell lines and primary cells [1,2]. Morphine treatment has been associated with increased translocation of bacterial commensals or their associated molecular patterns (e.g., lipopolysaccharide) from the gut into the systemic lymphatic and blood circulation [3-7]. Moreover, animals treated with morphine exhibit greater susceptibility to enteric infections, including those produced by Salmonella enterica serovars Enteritidis and Typhimurium, Listeria monocytogenes, Vibrio cholerae, and Pseudomonas aeruginosa [8-11].

Epithelial cells constitute the first line of innate host defense in mucosal tissues and possess accessory immune functions [12]. In the gastrointestinal tract, epithelial cells in the intestinal mucosa appear to be innervated by opioid peptide-immunoreactive submucosal nerves and can interact with food-derived opioids such as casomorphins that are generated in the bowel lumen [13-15]. There is evidence that intestinal epithelial cells from several families of animals may express specific opioid binding sites [16-22]. The effects of morphine or other opioids on epithelial immune responses to pathobionts or pathogenic microorganisms have not been hitherto investigated. IPEC-J2 cells derived from the neonatal swine small intestine have been used extensively to study host-pathogen interactions between epithelial cells and entero-invasive or entero-adherent bacterial pathogens [23].

In this study, we utilized confluent, polarized IPEC-J2 cell monolayers to test the hypothesis that morphine modifies vectorial epithelial immune responses to entero-invasive $S$. Typhimurium or entero-adherent E. coli $\mathrm{O} 157: \mathrm{H7}$, and their associated molecular patterns, i.e. flagellin and lipopolysaccharide.

\section{Results and Discussion}

\subsection{Effect of Morphine on Epithelial Immune Responses to Enteric Pathogens}

Interleukin-6 secretion was significantly increased in the apical media bathing epithelial monolayers exposed to $E$. coli or $S$. Typhimurium for $6 \mathrm{hr}$ relative to monolayers unexposed to the bacteria (Figure 1). In addition, these two pathogenic bacteria evoked increases in bi-directional IL-8 secretion from the monolayers (Table 1). The present results with $S$. Typhimurium are in concordance with those reported previously by Skjolaas et al. [24,25], IPEC-J2 cell monolayers released the cytokine IL-6 into the apical (mucosal) medium and the chemokine IL-8 into both the apical and basolateral (serosal) media after bacterial exposure. On the other hand, the finding that strain 85-170 of Shiga toxin-negative E. coli O157:H7 elicits vectorial secretion of IL-6 and IL-8 from IPEC-J2 monolayers has not been hitherto reported.

Morphine pretreatment significantly decreased IL-6 secretion from E. coli-treated monolayers by a naloxone-sensitive mechanism (Figure 1A), but did not decrease IL-6 secretion in response to $S$. Typhimurium (Figure 1B). The apparent lack of morphine effect on the relatively large cytokine 
responses of monolayers to $S$. Typhimurium, an entero-invasive pathogen, suggests that either $E$. coli and Salmonella may be acting through different intracellular signaling pathways to elicit directional cytokine secretion or that the more robust effects of Salmonella on epithelial interleukin secretion could not be attenuated by morphine, at least at the concentration tested. In a separate group of six experiments, the anti-inflammatory steroid dexamethasone significantly blunted the increase in apical IL-6 secretion evoked by Salmonella exposure $(118.35 \pm 9.60 \mathrm{pg} / \mathrm{mL}$ IL-6 versus $69.14 \pm 8.12 \mathrm{pg} / \mathrm{mL}$ IL-6 in monolayers untreated or pre-treated with dexamethasone respectively, $\mathrm{N}=6$ replicates, analyzed by Student's $t$ test, $p<0.01$ ). Dexamethasone had no effect on IL-8 secretion (data not shown). In human corneal and bronchial epithelial cells, dexamethasone reportedly inhibits both IL-6 and IL-8 secretion evoked by pro-inflammatory mediators [26-28]. Morphine alone or in combination with naloxone did not modify constitutive cytokine release from cell monolayers that were unexposed to bacteria and did not alter epithelial IL-8 responses to either pathogen (data not shown).

Figure 1. Morphine attenuates apical IL-6 secretion in IPEC-J2 monolayers exposed to entero-adherent E. coli or entero-invasive salmonellae. IPEC-J2 cell monolayers were grown to confluency in Transwells. Morphine $(10 \mu \mathrm{M}) \pm$ naloxone $(1 \mu \mathrm{M})$ was added to the basolateral medium 30 minutes before the addition of E. coli $0157: \mathrm{H} 7$ or $S$. Typhimurium $\left(10^{7}\right.$ colony-forming units (CFUs)) to the apical medium. After a $6 \mathrm{hr}$ incubation, the apical medium was collected and analyzed by ELISA for IL-6. (A) E. coli. *Significantly higher than apical medium-only control by one-way ANOVA $[F(3,32)=4.716, p=0.0078]$ and Tukey's post-hoc test. $\mathrm{N}=9$ replicates (one condition/monolayer in each of nine different experiments). (B) $S$. Typhimurium. *Significantly higher than apical medium-only control by one-way ANOVA $[F(2,21)=15.78, p<0.0001]$ and Tukey's post-hoc test. $\mathrm{N}=8$ replicates (one condition/monolayer in each of eight different experiments).

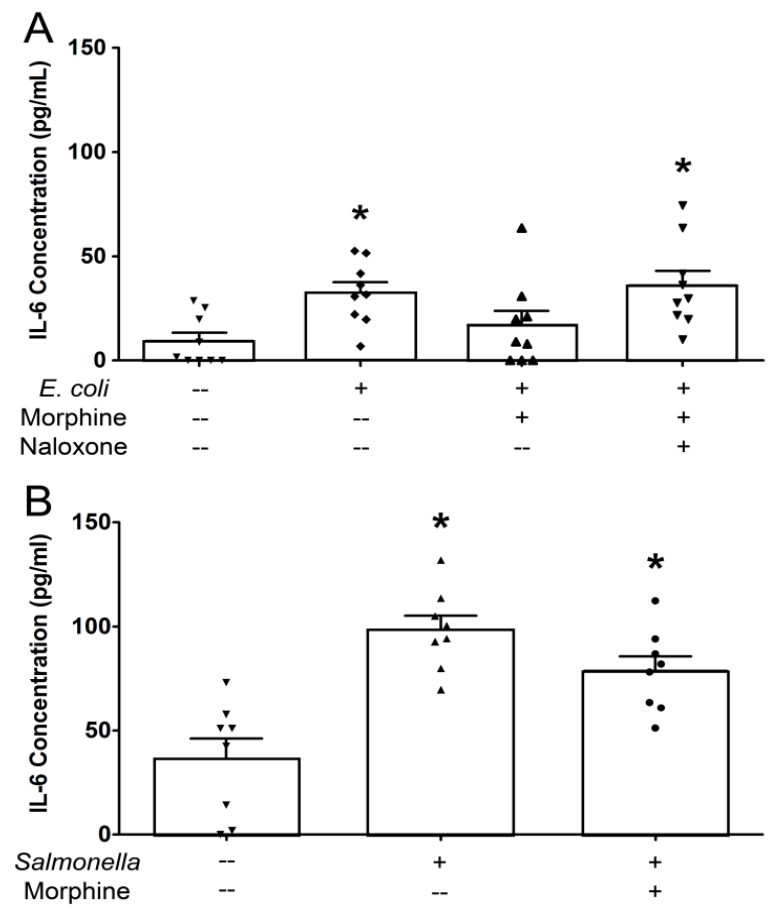


Table 1. Effects of E. coli $0157: \mathrm{H} 7$ and S. enterica Typhimurium on Polarized IL-8 Secretion from IPEC J2 Cell Monolayers.

\begin{tabular}{|c|c|c|c|c|c|c|}
\hline & Control & E. coli & $p$ value & Control & S. Typhimurium & $p$ value \\
\hline $\begin{array}{l}\text { Apical IL-8 } \\
\text { concentration }\end{array}$ & $\begin{array}{c}101.92 \pm \\
4.54\end{array}$ & $\begin{array}{c}425.60 \pm \\
20.12\end{array}$ & 0.0015 & $\begin{array}{c}143.72 \\
\pm 16.98\end{array}$ & $1129.74 \pm 50.37$ & $<0.001$ \\
\hline $\begin{array}{c}\text { Basolateral IL-8 } \\
\text { concentration }\end{array}$ & $\begin{array}{c}16.68 \pm \\
2.78 \\
\end{array}$ & $\begin{array}{c}1188.47 \pm \\
45.02 \\
\end{array}$ & $<0.001$ & $\begin{array}{c}48.14 \pm \\
14.43 \\
\end{array}$ & $2516.64 \pm 66.17$ & $<0.001$ \\
\hline $\begin{array}{l}\text { Values are express } \\
(\mathrm{N}=\text { one condition }\end{array}$ & $\begin{array}{l}\text { as mean } \pm \\
\text { nolayer in }\end{array}$ & $\begin{array}{l}\text { of IL- } 8 \text { cor } \\
\text { ch of } 9 \text { and } 8\end{array}$ & $\begin{array}{l}\text { atration } \\
\text { perimen }\end{array}$ & $\begin{array}{l}\mathrm{g} / \mathrm{mL} \text { of } \\
\text { ith } E . c c\end{array}$ & $\begin{array}{l}\text { ical or basolateral ba } \\
\text { and } S \text {. Typhimurium, }\end{array}$ & $\begin{array}{l}\text { g medium } \\
\text { gectively) }\end{array}$ \\
\hline
\end{tabular}

2.2. Effects of Morphine on Immune Responses by Epithelial Monolayers Exposed to Pathogen-Associated Molecular Patterns

The bacterial products lipopolysaccharide (LPS) and flagellin, agonists at TLR-4 and TLR-5 respectively, stimulated bi-directional IL-8, but not IL-6 secretion from epithelial monolayers when administered in combination (Figure 2). Their combined effect on apical IL-8 secretion was some 10 to 30 fold less than that evoked by exposure of monolayers to E. coli or $S$. Typhimurium. Apically-directed IL-8 secretion in response to the TLR agonists was inhibited by morphine, an effect that was sensitive to naloxone (Figure 2).

Figure 2. Morphine attenuates apical IL-8 secretion in IPEC-J2 monolayers exposed to lipopolysaccharide (LPS) and flagellin. IPEC-J2 cell monolayers were grown to confluency in Transwells. Morphine $(10 \mu \mathrm{M}) \pm$ naloxone $(1 \mu \mathrm{M})$ was added to the basolateral medium 30 minutes before the addition of LPS $(1 \mu \mathrm{g} / \mathrm{mL})$ to the apical medium and flagellin $(100$ $\mathrm{ng} / \mathrm{mL}$ ) to the basolateral medium. After a $6 \mathrm{hr}$ incubation, the apical medium was collected and analyzed by ELISA for IL-8. * Significantly different than medium-only control by one-way ANOVA $[F(3,12)=4.853, p=0.0195]$ and Tukey's post-hoc test. $\mathrm{N}=4$ replicates (one condition/monolayer in each of four different experiments).

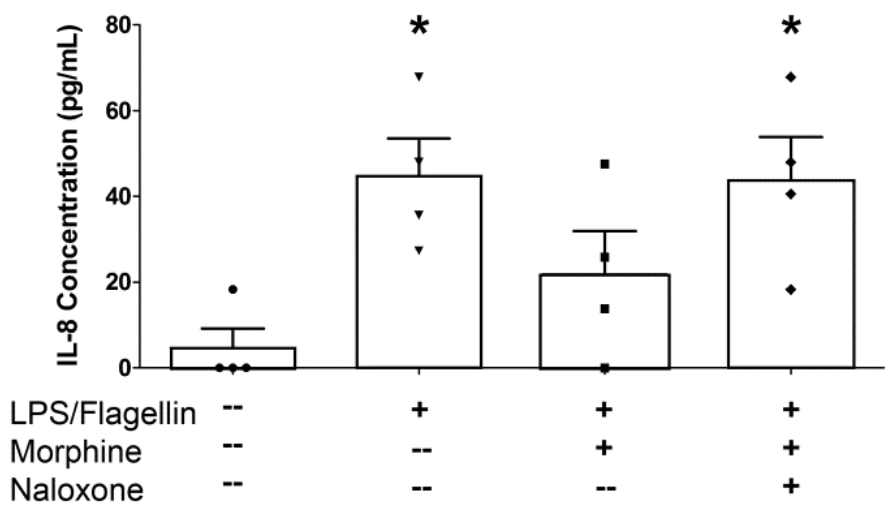

Morphine pretreatment had no effect on TLR-elicited basolateral IL-8 secretion (data not shown). The chemokine IL-8 plays an important role in recruiting neutrophils to the intestinal epithelial surface [29]. 
Morphine and other opioid agonists have been reported to interact non-competitively with TLR-4 in glia and other immuno-competent cells at a naloxone-insensitive site of action [30,31]. In the present study, the naloxone-sensitive effect of morphine in decreasing LPS-induced IL-8 secretion is likely due to an opioid receptor-dependent mechanism and not to direct interactions with TLR-4. If morphine actions are extrapolated to the extensive surface area of the intestinal mucosa, we hypothesize that reductions in IL-8 or IL-6 concentrations at the mucosal surface might impair neutrophil chemotaxis and activation, leading to an increased susceptibility to mucosal infection with potential bacterial translocation and sepsis $[32,33]$.

\section{Experimental Section}

\subsection{Reagents}

Porcine jejunal epithelial IPEC-J2 cells were a gift from Bruce Schultz (Department of Anatomy and Physiology, College of Veterinary Medicine, Kansas State University, Manhattan, KS, USA). Cells were cultured as previously described [23].

A swine isolate of Salmonella enterica serovar Typhimurium DT104 was provided by Jeffrey Bender (Center for Animal Health and Food Safety, University of Minnesota, St. Paul, MN, USA) and has been previously described [34]. Strain 85-170 of Shiga toxin-negative Escherichia coli O157:H7 was provided by Mark Stevens (Roslin Institute and Royal (Dick) School of Veterinary Studies, University of Edinburgh, Midlothian, EH25 9RG Scotland, UK) and has also been previously described [35,36]. All bacteria were grown in Luria-Bertani (LB) broth at $37^{\circ} \mathrm{C}$ with $5 \% \mathrm{CO}_{2}$.

Morphine sulfate was obtained from the National Institute on Drug Abuse (Bethesda, MD, USA). Naloxone, dexamethasone and lipopolysaccharide (LPS, purified from $S$. Typhimurium) were obtained from Sigma-Aldrich (St. Louis, MO, USA). Flagellin was purchased from Enzo Life Sciences (Farmingdale, NY, USA).

\subsection{IPEC-J2 Experiments}

Cells were grown to confluency on $0.4 \mu \mathrm{m}$ pore-size Transwell ${ }^{\circledR}$ filters (Corning, Tewksbury, MA) and tested for trans-epithelial electrical resistances (TEERs) $>700 \Omega$, indicative of a confluent monolayer. Cell monolayers were washed and incubated in antibiotic-free medium one day prior to experimentation. On the day of experimentation, TEERs of $>400 \Omega$ across each monolayer were confirmed. Morphine $(10 \mu \mathrm{M}) \pm$ naloxone $(1 \mu \mathrm{M})$ was added to the basolateral medium for 30 minutes prior to the addition of bacteria ( $10^{7}$ colony-forming units, CFUs) to the apical medium. In one set of experiments, LPS $(1 \mu \mathrm{g} / \mathrm{mL})$ was added to the apical medium instead of bacteria with the simultaneous addition of flagellin $(100 \mu \mathrm{g} / \mathrm{mL})$ to the basolateral medium. These concentrations of LPS and flagellin chosen were previously reported to evoke maximal chemokine release from cultured IPEC-J2 cells [37] and human HT29 colonic adenocarcinoma cells [38], respectively. Some experiments with dexamethasone $(1 \mu \mathrm{M})$, an anti-inflammatory glucocorticoid, were also conducted; it was added to the basolateral medium for 30 minutes prior to the addition of bacteria $\left(10^{7} \mathrm{CFUs}\right)$ to the apical medium. All experiments were carried out over $6 \mathrm{~h}$, at which point apical and basolateral media were collected, 
centrifuged to remove bacteria, and frozen at $-20{ }^{\circ} \mathrm{C}$ until ELISA analysis. ELISA analysis of secreted proteins was determined using porcine Quantikine kits (R\&D Systems, Minneapolis, MN).

\section{Conclusions}

In the present study, morphine decreased apical secretion of IL-6 or IL-8 from porcine intestinal epithelial cells in response to entero-adherent E. coli $\mathrm{O} 157: \mathrm{H} 7$ or bacteria-associated molecular patterns, respectively. To our knowledge, this is the first report of an opioid action on immune responses in non-transformed intestinal epithelial cells in vitro. However, investigations in vivo indicate that MOR agonists decrease injury and inflammatory responses in intestinal epithelial cells [39-41]. The effects of morphine were inhibited by the general opioid receptor antagonist naloxone, suggesting that they are mediated by opioid receptors. Indeed, mRNAs for MOR and DOR have been detected at low levels of expression in IPEC-J2 cells (A.J. Brosnahan and D.R. Brown, unpublished results). The opioid alkaloid preferentially interacts with MOR, but can interact with DOR at higher concentrations [42]. Although the opioid receptor type(s) and mechanisms underlying the action of morphine were not investigated here, inhibitory interactions between opioid agonists and pro-inflammatory transcription factors, notably nuclear factor kappaB, have been reported to occur in leukocytes [43-46]. Future studies should be designed to explore this and other possible mechanisms of opioid action in epithelial cells.

Epithelial cells comprise the first line of defense against potential pathogens in the gut. They constitute a physical barrier against microbial penetration and detect invading microorganisms and communicate to neighboring innate immune cells through the production and vectorial release of various cytokines and chemokines. Perturbations in the process of epithelial cell to immunocyte communication by opiates such as morphine and perhaps other drugs used in the palliative care of immuno-compromised patients may further impair disease resistance and worsen the subsequent course of intestinal infections.

\section{Acknowledgments}

The authors thank Michael P. Murtaugh (Department of Veterinary and Biomedical Sciences, College of Veterinary Medicine, University of Minnesota, St. Paul, MN, USA) for his valuable advice concerning the research undertaken here, as well as the use of primers, equipment, and other materials in his laboratory. This work was supported by NIH-NIDA DA-10200 (DRB). Postdoctoral support for AJB was provided by NIH-NIDA training grant T32DA007097.

\section{Author Contributions}

Amanda J. Brosnahan and David R. Brown designed the experiments, evaluated the results, and wrote this article. Amanda J. Brosnahan, Bryan J. Jones, Cheryl M. Dvorak collected and analyzed the data. All authors approved the published version.

\section{Conflicts of Interest}

The authors declare no conflict of interest. 


\section{References and Notes}

1. Roy, S.; Ninkovic, J.; Banerjee, S.; Charboneau, R.G.; Das, S.; Dutta, R.; Kirchner, V.A.; Koodie, L.; Ma, J.; Meng, J.; et al. Opioid drug abuse and modulation of immune function: Consequences in the susceptibility to opportunistic infections. J. Neuroimmune Pharmacol. 2011, 6, 442-465.

2. Bidlack, J.M.; Khimich, M.; Parkhill, A.L.; Sumagin, S.; Sun, B.; Tipton, C.M. Opioid receptors and signaling on cells from the immune system. J. Neuroimmune Pharmacol. 2006, 1, 260-269.

3. Leslie, K.A.; Behme, R.; Clift, A.; Martin, S.; Grant, D.; Duff, J.H. Synergistic effects of tumour necrosis factor and morphine on gut barrier function. Can. J. Surg. 1994, 37, 143-147.

4. Hilburger, M.E.; Adler, M.W.; Truant, A.L.; Meissler, J.J., Jr.; Satishchandran, V.; Rogers, T.J.; Eisenstein, T.K. Morphine induces sepsis in mice. J. Infect. Dis. 1997, 176, 183-188.

5. Roy, S.; Charboneau, R.G.; Barke, R. A. Morphine synergizes with lipopolysaccharide in a chronic endotoxemia model. J. Neuroimmunol. 1999, 95, 107-114.

6. Ocasio, F.M.; Jiang, Y.; House, S.D.; Chang, S.L. Chronic morphine accelerates the progression of lipopolysaccharide-induced sepsis to septic shock. J. Neuroimmunol. 2004, 149, 90-100.

7. Runkel, N.S.; Moody, F.G.; Smith, G.S.; Rodriguez, L.F.; Chen, Y.; Larocco, M.T.; Miller, T.A. Alterations in rat intestinal transit by morphine promote bacterial translocation. Dig. Dis. Sci. 1993, 38, 1530-1536.

8. Asakura, H.; Kawamoto, K.; Igimi, S.; Yamamoto, S.; Makino, S. Enhancement of mice susceptibility to infection with Listeria monocytogenes by the treatment of morphine. Microbiol. Immunol. 2006, 50, 543-547.

9. Cray, W.C., Jr.; Tokunaga, E.; Pierce, N.F. Successful colonization and immunization of adult rabbits by oral inoculation with Vibrio cholerae O1. Infect. Immun. 1983, 41, 735-741.

10. Babrowski, T.; Holbrook, C.; Moss, J.; Gottlieb, L.; Valuckaite, V.; Zaborin, A.; Poroyko, V.; Liu, D.C.; Zaborina, O.; Alverdy, J.C. Pseudomonas aeruginosa virulence expression is directly activated by morphine and is capable of causing lethal gut-derived sepsis in mice during chronic morphine administration. Ann. Surg. 2012, 255, 386-393.

11. MacFarlane, A.S.; Peng, X.; Meissler, J.J., Jr.; Rogers, T.J.; Geller, E.B.; Adler, M.W.; Eisenstein, T.K. Morphine increases susceptibility to oral Salmonella typhimurium infection. J. Infect. Dis. 2000, 181, 1350-1358.

12. Pott, J.; Hornef, M. Innate immune signalling at the intestinal epithelium in homeostasis and disease. EMBO Rep. 2012, 13, 684-698.

13. Holzer, P. Opioid receptors in the gastrointestinal tract. Regul. Pept. 2009, 155, 11-17.

14. Martinez-Maqueda, D.; Miralles, B.; de Pascual-Teresa, S.; Reveron, I.; Munoz, R.; Recio, I. Food-derived peptides stimulate mucin secretion and gene expression in intestinal cells. J. Agric. Food Chem. 2012, 60, 8600-8605.

15. Shimizu, M.; Son, D.O. Food-derived peptides and intestinal functions. Curr. Pharm. Des. 2007, 13, 885-895.

16. Quito, F.L.; Seybold, V.S.; Brown, D.R. Opiate binding sites in mucosa of pig small intestine. Life Sci. 1991, 49, 219-222.

17. Neudeck, B.L.; Loeb, J.; Buck, J. Activation of the kappa-opioid receptor in Caco-2 cells decreases interleukin-8 secretion. Eur. J. Pharmacol. 2003, 467, 81-84. 
18. Neudeck, B.L.; Loeb, J.M. Endomorphin-1 alters interleukin-8 secretion in Caco-2 cells via a receptor mediated process. Immunol. Lett. 2002, 84, 217-221.

19. Zoghbi, S.; Trompette, A.; Claustre, J.; El Homsi, M.; Garzon, J.; Jourdan, G.; Scoazec, J.Y.; Plaisancie, P. Beta-Casomorphin-7 regulates the secretion and expression of gastrointestinal mucins through a mu-opioid pathway. Am. J. Physiol. Gastrointest. Liver Physiol. 2006, 290, G1105-G1113.

20. Nano, J.L.; Fournel, S.; Rampal, P. Characterization of delta-opioid receptors and effect of enkephalins on IRD 98 rat epithelial intestinal cell line. Pflugers. Arch. 2000, 439, 547-554.

21. Lang, M.E.; Davison, J.S.; Bates, S.L.; Meddings, J.B. Opioid receptors on guinea-pig intestinal crypt epithelial cells. J. Physiol. 1996, 497, 161-174.

22. Nylund, G.; Pettersson, A.; Bengtsson, C.; Khorram-Manesh, A.; Nordgren, S.; Delbro, D.S. Functional expression of mu-opioid receptors in the human colon cancer cell line, HT-29, and their localization in human colon. Dig. Dis. Sci. 2008, 53, 461-466.

23. Brosnahan, A.J.; Brown, D.R. Porcine IPEC-J2 intestinal epithelial cells in microbiological investigations. Vet. Microbiol. 2012, 156, 229-237.

24. Skjolaas, K.A.; Burkey, T.E.; Dritz, S.S.; Minton, J.E. Effects of Salmonella enterica serovars Typhimurium (ST) and Choleraesuis (SC) on chemokine and cytokine expression in swine ileum and jejunal epithelial cells. Vet. Immunol. Immunopathol. 2006, 111, 199-209.

25. Skjolaas, K.A.; Burkey, T.E.; Dritz, S.S.; Minton, J.E. Effects of Salmonella enterica serovar Typhimurium, or serovar Choleraesuis, Lactobacillus reuteri and Bacillus licheniformis on chemokine and cytokine expression in the swine jejunal epithelial cell line, IPEC-J2. Vet. Immunol. Immunopathol. 2007, 115, 299-308.

26. Cao, J.; Ren, G.; Gong, Y.; Dong, S.; Yin, Y.; Zhang, L. Bronchial epithelial cells release IL-6, CXCL1 and CXCL8 upon mast cell interaction. Cytokine 2011, 56, 823-831.

27. Djalilian, A.R.; Nagineni, C.N.; Mahesh, S.P.; Smith, J.A.; Nussenblatt, R.B.; Hooks, J.J. Inhibition of inflammatory cytokine production in human corneal cells by dexamethasone, but not cyclosporin. Cornea 2006, 25, 709-714.

28. Levine, S.J.; Larivee, P.; Logun, C.; Angus, C.W.; Shelhamer, J.H. Corticosteroids differentially regulate secretion of IL-6, IL-8, and G-CSF by a human bronchial epithelial cell line. Am. J. Physiol. 1993, 265, L360-368.

29. McCormick, B.A.; Colgan, S.P.; Delp-Archer, C.; Miller, S.I.; Madara, J.L. Salmonella Typhimurium attachment to human intestinal epithelial monolayers: Transcellular signalling to subepithelial neutrophils. .J. Cell Biol. 1993, 123, 895-907.

30. Stevens, C.W.; Aravind, S.; Das, S.; Davis, R.L. Pharmacological characterization of LPS and opioid interactions at the Toll-like receptor 4. Br. J. Pharmacol. 2013, 168, 1421-1429.

31. Watkins, L.R.; Hutchinson, M.R.; Rice, K.C.; Maier, S.F. The "toll" of opioid-induced glial activation: Improving the clinical efficacy of opioids by targeting glia. Trends Pharmacol. Sci. 2009, 30, 581-591.

32. Nadeau, W.J.; Pistole, T.G.; McCormick, B.A. Polymorphonuclear leukocyte migration across model intestinal epithelia enhances Salmonella typhimurium killing via the epithelial derived cytokine, IL-6. Microbes. Infect. 2002, 4, 1379-1387. 
33. Sitaraman, S.V.; Merlin, D.; Wang, L.; Wong, M.; Gewirtz, A.T.; Si-Tahar, M.; Madara, J.L. Neutrophil-epithelial crosstalk at the intestinal lumenal surface mediated by reciprocal secretion of adenosine and IL-6. J. Clin. Invest. 2001, 107, 861-869.

34. Schmidt, L.D.; Kohrt, L.J.; Brown, D.R. Comparison of growth phase on Salmonella enterica serovar Typhimurium invasion in an epithelial cell line (IPEC J2) and mucosal explants from porcine small intestine. Comp Immunol. Microbiol. Infect. Dis. 2008, 31, 63-69.

35. Chen, C.; Lyte, M.; Stevens, M.P.; Vulchanova, L.; Brown, D.R. Mucosally-directed adrenergic nerves and sympathomimetic drugs enhance non-intimate adherence of Escherichia coli O157:H7 to porcine cecum and colon. Eur. J. Pharmacol. 2006, 539, 116-124.

36. Tzipori, S.; Karch, H.; Wachsmuth, K.I.; Robins-Browne, R.M.; O’Brien, A.D.; Lior, H.; Cohen, M.L.; Smithers, J.; Levine, M.M. Role of a 60-megadalton plasmid and Shiga-like toxins in the pathogenesis of infection caused by enterohemorrhagic Escherichia coli O157:H7 in gnotobiotic piglets. Infect. Immun. 1987, 55, 3117-3125.

37. Arce, C.; Ramirez-Boo, M.; Lucena, C.; Garrido, J.J. Innate immune activation of swine intestinal epithelial cell lines (IPEC-J2 and IPI-2I) in response to LPS from Salmonella typhimurium. Comp Immunol. Microbiol. Infect. Dis. 2010, 33, 161-174.

38. Bannon, C.; Davies, P.J.; Collett, A.; Warhurst, G. Potentiation of flagellin responses in gut epithelial cells by interferon-gamma is associated with STAT-independent regulation of MyD88 expression. Biochem. J. 2009, 423, 119-128.

39. Philippe, D.; Dubuquoy, L.; Groux, H.; Brun, V.; Chuoï-Mariot, M.T.; Gaveriaux-Ruff, C.; Colombel, J.F.; Kieffer, B.L.; Desreumaux, P. Anti-inflammatory properties of the mu opioid receptor support its use in the treatment of colon inflammation. J. Clin. Invest. 2003, 111, 1329-1338.

40. Goldsmith, J.R.; Uronis, J.M.; Jobin, C. Mu opioid signaling protects against acute murine intestinal injury in a manner involving Stat3 signaling. Am. J. Pathol. 2011, 179, 673-683.

41. Goldsmith, J.R.; Perez-Chanona, E.; Yadav, P.N.; Whistler, J.; Roth, B.; Jobin, C. Intestinal epithelial cell-derived $\mu$-opioid signaling protects against ischemia reperfusion injury through PI3K signaling. Am. J. Pathol. 2013, 182, 776-785.

42. Mignat, C.; Wille, U.; Ziegler, A. Affinity profiles of morphine, codeine, dihydrocodeine and their glucuronides at opioid receptor subtypes. Life Sci. 1995, 56, 79-799.

43. Roy, S.; Cain, K.J.; Chapin, R.B.; Charboneau, R.G.; Barke, R.A. Morphine modulates NF kappa B activation in macrophages. Biochem. Biophys. Res. Comm. 1998, 245, 392-396.

44. Welters, I.D.; Menzebach, A.; Goumon, Y.; Cadet, P.; Menges, T.; Hughes, T.K.; Hempelmann, G.; Stefano, G.B. Morphine inhibits NF-kappaB nuclear binding in human neutrophils and monocytes by a nitric oxide-dependent mechanism. Anesthesiology 2000, 92, 1677-1684.

45. Ye, R.D. Regulation of nuclear factor $\kappa \mathrm{B}$ activation by G-protein-coupled receptors. J. Leukoc. Biol. 2001, 70, 839-848.

46. Chen, Y.L.; Law, P.Y.; Loh, H.H. Nuclear factor kappaB signaling in opioid functions and receptor gene expression. J. Neuroimmune Pharmacol. 2006, 1, 270-279.

(C) 2014 by the authors; licensee MDPI, Basel, Switzerland. This article is an open access article distributed under the terms and conditions of the Creative Commons Attribution license (http://creativecommons.org/licenses/by/3.0/) 